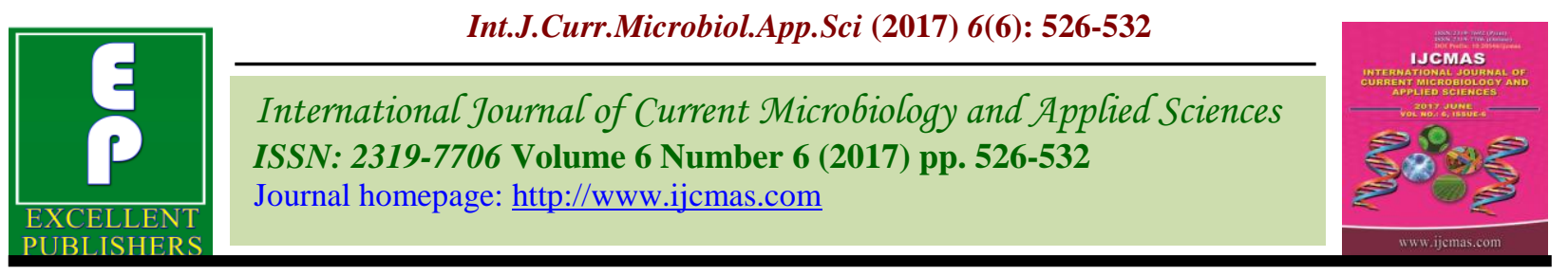

Original Research Article

https://doi.org/10.20546/ijcmas.2017.606.062

\title{
Effect of Biophysical Plant Characters on Okra Germplasm against Shoot and Fruit Borer
}

\author{
Sanjay Kumar ${ }^{1}$, R.C. Sharma ${ }^{2}$, Rajendra $\operatorname{Singh}^{3}$ and Sudhir Kumar ${ }^{3 *}$ \\ ${ }^{1}$ SMS (Plant Protection), KVK, Ujhani, Badaun (U.P.), India \\ ${ }^{2}$ Department of Entomology, NDUAT, Kumarganj, Faizabad (U.P.), India \\ ${ }^{3}$ Department of Entomology, Sardar Vallabhbhai Patel University of Agriculture and \\ Technology, Meerut (U.P.), India \\ *Corresponding author
}

A B S T R A C T

The experiment was conducted in the Student's Instructional farm of NDUAT, Faizabad during Kharif, 2012 and 2013 to evaluate the effects of various

Keywords

Biophysical characters,

Okra,

Shoot and fruit

borer,

Earias spp

Article Info

Accepted:

04 May 2017

Available Online:

10 June 2017 biophysical plant characters on twenty four okra germplasm against shoot and fruit borer, Earias spp. The results indicated that all the tested germplasm were significantly differed in relation to shoot and fruit borer population at shoot and fruit stages of the crop. The minimum fruits infestation was recorded on Arka Anamika germplasm (8.75 and 11.55\%) followed by NDO 67 (10.36 and 13.76\%) and the maximum was on Pusa Sawani (33.70 and 39.52\%) followed by VRO 6 (30.74 and 36.50\%) during the Kharif, 2012 and 2013, respectively. The plant height exhibited positive correlation $(\mathrm{r}=0.160,0.178)$ and $(\mathrm{r}=0.123,0.249)$ with shoot and fruit infestation, however, negative correlation were observed between number of branches/plant, fruit length, number of fruits/plant, fruit weight and yield during Kharif, 2012 and 2013, respectively. The morphological attributes showed no significant correlation between shoot and fruit damage on okra. Plant height, fruit length, diameter and color of the cultivars had no significant effect on the infestation of Earias spp.

\section{Introduction}

Okra (Abelmoschus esculentus L. Moench.) is an important vegetable crop of tropical and subtropical part of the world. The edible portion of the crop is the immature young pods which quickly loses its desirable characteristics at its maturity. India ranks first for okra production in the world. The total area covered under okra crop is about 530.80 thousand hectares with the production of 6350.30 Thousand MT green fruits, whereas the productivity is $12.0 \mathrm{MT} / \mathrm{ha}$. It is commercially grown in the state of Andhra Pradesh, West Bengal, Bihar, Gujarat, Maharashtra, Uttar Pradesh, Tamil Nadu, Karnataka, Haryana and Punjab etc. (Anonymous, 2013). About 13 insect pests have been reported to cause damage to okra (Mandal et al., 2006). Earias species alone did as high as 60-68 per cent damage in okra crop (Hiremath, 1984). It is one of the major 
limiting factors in the production of quality fruits of okra (Kharbade et al., 1998). The maximum damage of $52.4 \%$ buds and $67.6 \%$ fruits were reported by Dhawan and Sindhu (1984). Host plant resistance is a major part of IPM programme that saved the crop from this pest by making it less vulnerable or making the crop opposing to the pest. The morphological and biophysical characteristics of shoot and fruits are associated with attraction, feeding and oviposition of the pest therefore; the identification of biophysical characteristics from insect resistant varieties is most practical significance.

\section{Materials and Methods}

Various biophysical parameters associated with resistant to shoot and fruit borer were recorded on ten randomly selected plant at 60 days after sowing on twenty four okra germplasm i.e., plant height $(\mathrm{cm})$, no. of branches/plant, leaf color, stem surface, fruit surface, fruit color, length of fruits $(\mathrm{cm})$, number of fruits/plant, weight of fruit $(\mathrm{g})$ and yield/ plant (g). All such parameters were correlated with the incidence of the pest.

The plant height of each germplasm was measured from the base of the stem at ground level to the canopy of plant at the time of last picking of the fruits in centimeter and mean height of each germplasm was worked out. The total number of branches on 10 selected plants of each germplasm was counted and mean number of branches/plant was calculated. The colour of the leaves and fruits were categorized into three groups i.e., light green, green and dark green of the leaves and fruit. All the germplasm were thoroughly observed and categorized as per the visual appearance.

The Fruit and stem surface of each germplasm was categorized as smooth and rough by touching the leaf and fruit by hand. The total number of fruits/plant was calculated on ten randomly selected plants in all the germplasm. The length of 10 randomly selected fruits of each germplasm was measured in centimeter from the base of the pedicel to the tip of the fruit and mean of fruit length was worked out. The weight of fruits of each germplasm was measured at the time of each picking. Ten randomly selected fruits were taken in each replication and weighed. The total weight of fruit was divided by number of fruits and weight/fruit. The yield of produce was measured lot wise and converted into $\mathrm{Q} / /$ ha. All the data was analyzed as per standard statistical methods.

\section{Results and Discussion}

The experimental findings obtained on biophysical plant characteristics of okra germplasm in relation to the resistance of shoot and fruit borer during the Kharif, 2012 and Kharif, 2013 have been discussed.

\section{Biophysical plant characteristics}

The plant height ranged between 85.83 and $117.80 \mathrm{~cm}$ during Kharif, 2012 and between 86.50 and $118.33 \mathrm{~cm}$ during Kharif, 2013. The maximum plant height was recorded in Pusa Sawani, while the minimum was in germplasm NDO 59. Seven germplasm i.e., Pusa sawani, NDO 61, NDO 56, NDO 58, NDO 64, NDO 72 and NDO 63 showed maximum plant height.

Thirteen germplasm i.e., NDO-69, Arka Abhay, VRO 6, NDO 74, NDO 73, NDO 60, NDO 62, Arka Anamica, NDO 71, NDO 55, NDO 68, NDO 70 and NDO 67 showed medium height. Only four germplasm, NDO 66, NDO 57, NDO 65 and NDO 59, were short heightened germplasm during Kharif, 2012. In next Kharif season 2013, the same trends were observed in the plant height of the germplasm. 
During Kharif, 2012 number of branches per plant ranged from 1.40 to 4.83 and the maximum branches per plant was observed in germplasm NDO 74 followed by NDO 59, NDO 69, and NDO 70, respectively. Eleven germplasm were normal branched, while nine germplasm were less branched. During Kharif 2013, similar trend was also noticed in the range of 1.40 to 5.00 per plant but no significant correlation with per cent fruit damage was found.

The maximum fruit length was recorded in NDO $69 \quad(15.25 \mathrm{~cm})$ germplasm, while minimum was in NDO $62(8.20 \mathrm{~cm})$ during Kharif 2012.Ten germplasm had good fruit length i.e., NDO 69, NDO 74, NDO 70, NDO 72, NDO 67, NDO 73, NDO 56, NDO 63, NDO 58 and NDO 64, respectively. Seven germplasm i.e., Arka Anamica, NDO 57, NDO 71, NDO 65, NDO 59, Arka Abhay, and NDO 55 showed medium fruit length and seven germplasm NDO 66, NDO 60, Pusa Sawani, NDO 61, NDO 68, VRO 6 and NDO 62 noticed minimum fruit length. During Kharif 2013, the similar trends were obtained in the fruit length of the germplasm. These findings are in agreement with Gautam et al., (2013) who reported that morphological characters such as fruit length, seed, fruit hairs and diameter of fruit were Non significant with fruit infestation in okra.

Out of twenty four germplasm, ten germplasm showed maximum number of fruits per plant, while twelve germplasm i.e., NDO 57, Pusa Sawani, NDO 55, Arka Anamica, NDO 58, NDO 73, NDO 68, NDO 69, NDO 62, NDO 74, NDO 61 and NDO 64 had medium number of fruits per plant and two germplasm i.e., NDO 66 and NDO 65 possessed minimum number of fruits, respectively during both the Kharif, seasons.

The fruit weight ranged between 14.17 and $29.88 \mathrm{~g} /$ fruit during Kharif, 2012. In eleven germplasm were high fruit weight i.e., NDO56, NDO-58, NDO-72, NDO-69, NDO-70, NDO-67, Arka Anamica, NDO-71, NDO-74, NDO-57 and NDO-63, respectively. Seven germplasm i.e., NDO-73, NDO-68, NDO-60, NDO-66, NDO-62, NDO-64, Pusa sawani showed medium fruit weight and six germplasm that showed low fruit weight i.e., NDO-65, VRO-6, NDO-61, NDO-55, NDO59 and Arka Abhay. In next Kharif season 2013, fruit weight varied from 14.30 to 30.10 $\mathrm{g} /$ fruit and the maximum fruit weight was recorded in germplasm NDO-56 which was higher as compared to other germplasm, while minimum was in Arka Abhay.

In both the Kharif seasons, eight germplasm had dark green leaves i.e., NDO 55, NDO 56, NDO 59, NDO 63, NDO 64, NDO 65, NDO 69 and NDO 70 in which two germplasm namely; NDO 63 and NDO 70 were moderately resistant with 10.08 and 11.82 shoot and 13.48 and 14.87 per cent fruits damage, respectively. Remaining sixteen germplasm i.e., Pusa sawani, NDO 57, NDO 58, NDO 60, Arka Anamica, ArkaAbhay, VRO 6, NDO 61, NDO 62, NDO 66, NDO 67, NDO 68, NDO 71, NDO 72, NDO 73 and NDO 74 had green coloured leaves in which Arka Anamica, NDO 67 and NDO 73 were moderately resistant against shoot and fruit borer, while none of germplasm had light green colour leaf (Tables 1 and 2). Out of twenty four germplasm, only eight possessed dark green colour fruits in that the two germplasm namely, NDO 63 and NDO 70 had minimum per cent shoot and fruit damage in both the Kharif seasons. Remaining ten germplasm, namely NDO 59, Arka Abhay, NDO 61, NDO 65, NDO 66, NDO 67, NDO 71, NDO 72, NDO 73 and NDO 74 their fruits colour were green, while in six i.e., Pusa sawani, NDO 57, NDO 58, NDO 60, NDO 68 and VRO 6 germplasm mild or light green fruit colour were noticed during both the seasons. 
Table.1 Effect of biophysical parameters on the incidence of shoot and fruit borer in okra during Kharif, 2012

\begin{tabular}{|c|c|c|c|c|c|c|c|c|c|}
\hline $\begin{array}{l}\text { S. } \\
\text { No. }\end{array}$ & Germplasm & $\begin{array}{c}\text { Shoot } \\
\text { Damage \% }\end{array}$ & $\begin{array}{c}\text { Fruit } \\
\text { Damage } \%\end{array}$ & $\begin{array}{c}\text { Plant } \\
\text { Height }(\mathrm{cm})\end{array}$ & $\begin{array}{c}\text { No. of } \\
\text { Branches/PI }\end{array}$ & $\begin{array}{c}\text { Fruit } \\
\text { Length }(\mathbf{c m})\end{array}$ & Fruit/PI & $\begin{array}{l}\text { Weight/ } \\
\text { Fruit (g) }\end{array}$ & $\begin{array}{c}\text { Yield/Pl } \\
(\mathrm{g})\end{array}$ \\
\hline 1 & Pusa Sawani & 32.80 & 33.70 & 117.80 & 2.28 & 9.45 & 11.78 & 16.00 & 192.52 \\
\hline 2 & Arka Anamika & 22.15 & 24.51 & 105.33 & 2.63 & 11.88 & 11.31 & 20.83 & 246.75 \\
\hline 3 & Arka Abhay & 7.54 & 8.75 & 108.03 & 2.66 & 10.14 & 12.36 & 14.17 & 178.08 \\
\hline 4 & VRO-6 & 30.60 & 30.74 & 107.70 & 1.95 & 8.38 & 13.17 & 15.39 & 190.26 \\
\hline 5 & NDO-55 & 19.75 & 22.70 & 104.67 & 1.40 & 10.05 & 11.35 & 15.20 & 182.32 \\
\hline 6 & NDO-56 & 18.65 & 24.11 & 114.33 & 2.65 & 12.50 & 12.10 & 29.88 & 323.57 \\
\hline 7 & NDO-57 & 14.45 & 18.27 & 92.50 & 3.03 & 11.80 & 11.90 & 20.08 & 227.55 \\
\hline 8 & NDO-58 & 20.72 & 30.70 & 111.17 & 2.90 & 12.25 & 11.14 & 27.15 & 309.54 \\
\hline 9 & NDO-59 & 18.64 & 22.80 & 63.61 & 4.15 & 10.20 & 12.10 & 14.93 & 186.42 \\
\hline 10 & NDO-60 & 13.35 & 18.21 & 105.67 & 2.16 & 9.88 & 12.21 & 16.53 & 203.04 \\
\hline 11 & NDO-61 & 16.81 & 21.72 & 114.42 & 2.05 & 8.65 & 10.17 & 15.32 & 158.58 \\
\hline 12 & NDO-62 & 10.80 & 17.60 & 105.50 & 2.30 & 8.20 & 10.32 & 16.24 & 160.54 \\
\hline 13 & NDO-63 & 9.12 & 12.28 & 110.10 & 2.35 & 12.40 & 12.50 & 20.00 & 239.32 \\
\hline 14 & NDO-64 & 21.65 & 29.02 & 110.67 & 2.25 & 12.14 & 10.05 & 16.06 & 162.43 \\
\hline 15 & NDO-65 & 12.05 & 16.04 & 85.83 & 2.65 & 11.10 & 9.80 & 15.53 & 153.98 \\
\hline 16 & NDO-66 & 28.16 & 30.73 & 96.40 & 2.13 & 9.92 & 9.81 & 16.44 & 187.14 \\
\hline 17 & NDO-67 & 8.80 & 10.36 & 100.02 & 3.28 & 12.65 & 11.94 & 21.80 & 258.54 \\
\hline 18 & NDO-68 & 17.25 & 26.20 & 101.25 & 2.66 & 9.30 & 11.10 & 17.30 & 200.15 \\
\hline 19 & NDO-69 & 19.50 & 27.06 & 108.33 & 3.64 & 15.25 & 11.05 & 25.06 & 281.03 \\
\hline 20 & NDO-70 & 11.05 & 14.75 & 100.88 & 3.50 & 12.88 & 12.01 & 22.36 & 276.14 \\
\hline 21 & NDO-71 & 23.50 & 28.58 & 104.75 & 3.25 & 11.42 & 12.56 & 20.36 & 251.73 \\
\hline 22 & NDO-72 & 17.90 & 22.14 & 110.62 & 2.67 & 12.77 & 12.20 & 25.27 & 329.07 \\
\hline 23 & NDO-73 & 9.25 & 11.50 & 106.33 & 2.60 & 12.57 & 11.10 & 18.30 & 212.94 \\
\hline \multirow[t]{4}{*}{24} & NDO-74 & 19.50 & 27.73 & 106.58 & 4.83 & 13.68 & 10.20 & 20.22 & 205.51 \\
\hline & Mean & 17.67 & 20.09 & 103.85 & 2.75 & 11.23 & 11.43 & 19.18 & 221.55 \\
\hline & SEm \pm & 0.85 & 0.68 & 3.18 & 0.10 & 0.35 & 0.30 & 0.80 & 3.67 \\
\hline & $\mathrm{CD}$ at $5 \%$ & 2.41 & 1.95 & 9.05 & 0.30 & 0.99 & 0.85 & 2.30 & 10.44 \\
\hline
\end{tabular}


Table.2 Effect of biophysical parameters on the incidence of shoot and fruit borer in okra during Kharif, 2013

\begin{tabular}{|c|c|c|c|c|c|c|c|c|c|}
\hline $\begin{array}{l}\text { S. } \\
\text { No. }\end{array}$ & Germplasm & $\begin{array}{c}\text { Shoot } \\
\text { Damage \% }\end{array}$ & $\begin{array}{c}\text { Fruit } \\
\text { Damage \% }\end{array}$ & $\begin{array}{c}\text { Plant } \\
\text { Height }(\mathbf{c m})\end{array}$ & $\begin{array}{c}\text { No. of } \\
\text { Branches/PI }\end{array}$ & $\begin{array}{c}\text { Fruit } \\
\text { Length }(\mathbf{c m})\end{array}$ & Fruit/PI & $\begin{array}{l}\text { Weight/ } \\
\text { Fruit (g) }\end{array}$ & $\begin{array}{l}\text { Yield/PI } \\
\text { (g) }\end{array}$ \\
\hline 1 & Pusa Sawani & 35.10 & 39.52 & 118.33 & 2.33 & 9.55 & 11.92 & 16.17 & 195.78 \\
\hline 2 & Arka Anamika & 23.50 & 27.56 & 105.67 & 2.66 & 11.98 & 11.80 & 21.57 & 249.07 \\
\hline 3 & Arka Abhay & 9.20 & 11.55 & 108.50 & 2.68 & 10.24 & 12.64 & 14.30 & 182.15 \\
\hline 4 & VRO-6 & 33.70 & 36.50 & 108.17 & 2.00 & 8.66 & 13.21 & 15.60 & 195.02 \\
\hline 5 & NDO-55 & 20.15 & 23.43 & 105.00 & 1.40 & 10.12 & 11.80 & 15.40 & 185.10 \\
\hline 6 & NDO-56 & 22.60 & 26.36 & 114.67 & 2.66 & 12.84 & 12.25 & 30.10 & 334.73 \\
\hline 7 & NDO-57 & 18.50 & 19.28 & 92.84 & 3.10 & 11.92 & 11.93 & 20.20 & 229.47 \\
\hline 8 & NDO-58 & 23.70 & 28.10 & 111.67 & 3.00 & 12.53 & 11.38 & 27.20 & 311.29 \\
\hline 9 & NDO-59 & 21.30 & 23.25 & 73.67 & 4.33 & 10.52 & 12.16 & 15.30 & 188.33 \\
\hline 10 & NDO-60 & 15.20 & 22.76 & 106.33 & 2.32 & 9.97 & 12.39 & 16.70 & 205.57 \\
\hline 11 & NDO-61 & 17.56 & 25.18 & 117.17 & 2.12 & 9.33 & 10.18 & 15.40 & 161.93 \\
\hline 12 & NDO-62 & 18.50 & 26.70 & 106.15 & 2.33 & 8.23 & 10.34 & 16.37 & 163.77 \\
\hline 13 & NDO-63 & 11.05 & 14.68 & 110.25 & 2.37 & 12.60 & 12.66 & 20.13 & 243.13 \\
\hline 14 & NDO-64 & 23.70 & 32.10 & 111.50 & 2.33 & 12.42 & 10.11 & 16.20 & 168.90 \\
\hline 15 & NDO-65 & 15.54 & 18.51 & 86.50 & 2.66 & 11.17 & 9.84 & 15.70 & 154.58 \\
\hline 16 & NDO-66 & 34.25 & 38.10 & 96.73 & 2.17 & 9.97 & 10.00 & 16.60 & 189.27 \\
\hline 17 & NDO-67 & 12.30 & 13.76 & 100.27 & 3.33 & 12.91 & 12.00 & 21.90 & 266.40 \\
\hline 18 & NDO-68 & 19.30 & 28.50 & 101.58 & 2.68 & 8.70 & 11.15 & 17.40 & 203.57 \\
\hline 19 & NDO-69 & 22.50 & 31.50 & 109.83 & 3.68 & 15.33 & 11.13 & 25.60 & 289.65 \\
\hline 20 & NDO-70 & 12.60 & 15.00 & 101.35 & 3.66 & 13.07 & 12.13 & 22.43 & 280.75 \\
\hline 21 & NDO-71 & 30.50 & 33.50 & 105.33 & 3.33 & 11.46 & 12.87 & 21.10 & 253.42 \\
\hline 22 & NDO-72 & 18.56 & 23.15 & 111.00 & 2.74 & 12.97 & 12.37 & 25.70 & 338.71 \\
\hline 23 & NDO-73 & 13.18 & 16.50 & 107.67 & 2.62 & 12.90 & 11.17 & 20.10 & 215.41 \\
\hline \multirow[t]{4}{*}{24} & NDO-74 & 21.65 & 30.16 & 107.69 & 5.00 & 13.77 & 10.25 & 20.50 & 207.44 \\
\hline & Mean & 20.59 & 25.24 & 104.91 & 2.81 & 11.38 & 11.57 & 19.49 & 225.44 \\
\hline & SEm \pm & 0.65 & 0.61 & 2.73 & 0.10 & 0.20 & 0.24 & 0.81 & 6.30 \\
\hline & $\mathrm{CD}$ at $5 \%$ & 1.84 & 1.73 & 7.76 & 0.30 & 0.58 & 0.68 & 2.30 & 17.93 \\
\hline
\end{tabular}

Table.3 Correlation coefficient of per cent shoot and fruit damage with biophysical parameters in okra during Kharif, 2012 and 2013

\begin{tabular}{|c|c|c|c|c|c|c|c|}
\hline Year & Damage & $\begin{array}{c}\text { Plant Height } \\
(\mathrm{cm})\end{array}$ & No. of branches & Fruit Length $(\mathrm{cm})$ & Fruit/ Plant & $\begin{array}{c}\text { Weight/ Fruit } \\
\text { (g) }\end{array}$ & Yield/ Plant (g) \\
\hline \multirow[t]{2}{*}{2012} & Shoot & 0.160 & -0.148 & -0.219 & -0.014 & -0.041 & -0.024 \\
\hline & Fruit & 0.178 & -0.017 & -0.111 & -0.172 & 0.094 & 0.045 \\
\hline \multirow[t]{2}{*}{2013} & Shoot & 0.123 & -0.116 & -0.246 & -0.033 & -0.032 & -0.042 \\
\hline & Fruit & 0.249 & -0.103 & -0.243 & -0.204 & -0.044 & -0.096 \\
\hline
\end{tabular}

Non-significant at 1 and 5\% levels 
These findings are in accordance with Sharma and Jat (2009) where the authors argued that the Plant height, fruit length, diameter and colour of the cultivars had no significant effect on the infestation of Earias spp. Based on stem surface, only six germplasm had rough stem i.e., Pusa Sawani, Arka Abhay, NDO 57, NDO 58, NDO 64 and NDO 67 in which only two germplasm i.e., Arka Abhay and NDO 67 recorded with minimum shoot and fruit infestation. Remaining eighteen germplasm had smooth stem surface i.e., NDO 55, NDO 56, NDO 59, NDO 60, Arka Anamica, VRO 6, NDO 61, NDO 62, NDO 63, NDO 65, NDO 66, NDO 68, NDO 69, NDO 70, NDO 71, NDO 72, NDO 73 and NDO 74.

Among 24 okra germplasm, five showed rough texture i.e., Arka Anamica, Arka Abhay, NDO 57, NDO 65 and NDO 70 in which two germplasm namely, Arka Abhay and NDO 70 were moderately resistant against shoot and fruit borer. Remaining nineteen germplasm had smooth surface i.e., Pusa Sawani, NDO 55, NDO 56, NDO 58, NDO 59, NDO 60, VRO 6, NDO 61, NDO 62, NDO 63, NDO 64, NDO 66, NDO 67, NDO 68, NDO 69, NDO 71, NDO 72, NDO 73 and NDO 74 in which five germplasm namely; Pusa Sawani, VRO 6, NDO 64, NDO 66 and NDO 71 were susceptible.

\section{Yield}

Out of twenty four germplasm, NDO 72 gave the maximum yield per plant and that was significantly superior over the others, while minimum yield was obtained in NDO 65 that was varied from 153.98 to $329.07 \mathrm{~g} /$ plant. Three germplasm i.e., NDO 72, NDO 56 and NDO 58 showed maximum fruit yield/plant. Eleven germplasm i.e., NDO 69, NDO 70, NDO 67, NDO 71, Arka Anamica, NDO 63, NDO 57, NDO 73, NDO 74, NDO 60 and NDO 68 showed medium fruit yield/plant. Ten germplasm i.e., Pusa Sawani, VRO 6,
NDO 66, NDO 59, NDO 55, Arka Abhay, NDO 64, NDO 62, NDO 61 and NDO 65 gave minimum fruit yield. In next Kharif season 2013, fruit yield varied from 154.58 to $338.71 \mathrm{~g} /$ plant with similar trends.

\section{Correlation between biophysical parameters with mean per cent of shoot and fruit damage}

The data on the correlation between per cent shoot and fruit damage with biophysical parameters i.e., plant height, number of branches, fruit length, fruit weight and yield showed that only plant height was positively correlated with shoot and fruit damage $(\mathrm{r}=$ 0.160 and 0.178$)$ and $(r=0.123$ and 0.249$)$ during Kharif, 2012 and 2013, respectively. The number of branches $(\mathrm{r}=-0.148$ and $0.017)$ and $(r=-0.116$ and -0.103$)$, fruit length $(\mathrm{r}=-0.219$ and -0.111$)$ and $(\mathrm{r}=-0.246$ and $0.243)$, fruits per plant $(\mathrm{r}=-0.014$ and -0.172$)$ and $(r=-0.033$ and -0.204$)$ were negatively correlated with shoot and fruit damage during Kharif, 2012 and 2013, respectively. The fruit weight and yield per plant were negatively correlated at shoot damage in both seasons while, fruit weight and yield per plant $(\mathrm{r}=$ 0.094 and $\mathrm{r}$ 0.045) were positively correlated with fruit damage during Kharif, 2012 and negatively correlated during Kharif, 2013. All the bio-physical parameters tested in both the Kharif seasons were Non significant with shoot and fruit borer infestation. Similar findings were also reported by Dhankhar (1997), Alam Hossain (2008), Sharma and Jat (2009) and Gautam et al., (2013) where the authors argued that the plant height, fruit length, fruit hairs, diameter of fruit and colour of the cultivars had No significant effect with Earias spp infestation on okra (Table 3).

The present finding on correlation between fruit surface and percent fruit infestation showed that the smooth surfaces of fruit in general had more infestation as compared to 
rough texture. Sharma and Singh (2010) supported the present finding in which rough surfaced and medium sized fruit of okra were less infested by fruit borer.

\section{Acknowledgements}

The authors are thankful to Dr. M. S. Awalakh, Vice chancellor, and Dr. R.C Sharma, Associate Professor and Major Advisor, Department of Entomology, Narendra Deva University of Agriculture and Technology, Kumarganj, Faizabad for the unstinted support and other research facilities provided to carry out the investigation.

\section{References}

Alam, A. and Hossain, M.M. 2008. Variability of different growth contributing parameters of some okra (Abelmoschus esculentus L. Moench) accessions and their interrelation effects on yield. J. Agric Rural Dev., 6(1/2): 25-35.

Anonymous. 2013. Indian Horticulture Data Base-2013: Area, production and productivity of okra in India, Ministry of Agriculture, GOI, And Gurgaon: pp 301.

Dhankhar, B.S. 1997. Development of okra varieties resistant to biotic and abiotic stresses. In: U. K. Kohli and B. N. Kala (Eds.. Summer school on breeding for resistance to biotic and abiotic stresses in vegetable crops 21st February - 3rd March, 1997, Solan (H.P.): pp 79-82.

Dhawan, A.K. and Sidhu, A.S. 1984. Incidence and relative abundance of different species of spotted bollworms on okras at Ludhiana, Punjab. J. Res. Punjab Agri. Univ., 21(4): 533-542.

Gautam, H.K., Singh, N.N., Singh, C. and Rai, A.B. 2013. Morphological and biochemical characters in fruits against okra shoot and fruit borer (Earias vittella F). Indian. J. Entomol., 75(3): 189-193.

Hiremath, I.G. 1984. Host preference of spotted boll worms (Earias spp). Indian. J. Entomol., 9(3): 185-188.

Kharbade, S.B., Chandel, A.G. and Dethe, M.D. 1998. Bioeffecacy of Bacillus thuringiensis (Berliner) varietal products against E. vittella (Fab.) on okra. Pestol., 22(11): 8-10.

Mandal, S.K., Sah, S.B., Gupta, S.C. 2006. Screening of okra cultivars against Earias vitella. Ann. Pl. Protec. Sci., 14(2): 471-472.

Sharma, R. and Jat, B.L. 2009. Screening of okra varieties for resistance against shoot and fruit borer, Earias spp. Indian J. Plant Prot., 37(1/2): 178-180.

Sharma, B.N and Singh, S. 2010. Biophysical and biochemical factors of resistance in okra against shoot and fruit borer. Indian J. Entomol., 72(3): 212-216.

\section{How to cite this article:}

Sanjay Kumar, R.C. Sharma, Rajendra Singh and Sudhir Kumar. 2017. Effect of Biophysical Plant Characters on Okra Germplasm against Shoot and Fruit Borer. Int.J.Curr.Microbiol.App.Sci. 6(6): 526-532. doi: https://doi.org/10.20546/ijcmas.2017.606.062 